\title{
Extranjero/extraño: sujetos de desorden y discriminación. El caso de Bolivia, de Israel Adrián Caetano
}

\author{
Foreigner / stranger: subjects of disorder and discrimination. The case of \\ Bolivia, by Israel Adrián Caetano
}

\author{
Dra. María J. Villa \\ Universidad Nacional de Córdoba (Argentina)
}

Recibido: 10 de diciembre 2011

Aceptado: 29 de diciembre 2011

\section{Resumen}

En el marco de un proyecto mayor sobre los textos de la cultura en clave retórica, nos interesa analizar el lenguaje del llamado "nuevo cine argentino", y dentro de este movimiento, en esta ponencia, la película Bolivia de Israel Adrián Caetano (2001).

A través del film veremos la posibilidad figurativa de su discurso en cuanto a la conformación "orden" y "desorden" en los tejidos de las relaciones sociales, las retóricas de discriminación con sus lógicas de equivalencia y diferencia, construcción y deconstrucción de identidades, significaciones hegemónicas y antagónicas, formas de consideración de la "otredad" según parámetros que responden a concepciones de raza y/clase.

El llamado "nuevo cine argentino" es una corriente que se produjo a mediados de la década de los 90, en el marco de un país con problemas económicos y sociales, configurada en estrecha relación con ese contexto. Esto se plasma en filmes que expresaban males que afectan a la sociedad argentina en la expresión de una colectividad devastada por la crisis político-institucional, el desempleo y la discriminación reinante.

\begin{abstract}
Within the framework of a larger project on the texts of culture in a rhetorical key, we are interested in analyzing the language of the so-called "new Argentine cinema", and within this movement, in this presentation, the film Bolivia by Israel Adrián Caetano (2001)

Through the film we will see the figurative possibility of his discourse regarding the conformation of "order" and "disorder" in the tissues of social relations, the rhetorics of discrimination with its logics of equivalence and difference, construction and deconstruction of identities, meanings hegemonic and antagonistic, forms of consideration of "otherness" according to parameters that respond to conceptions of race and / class.
\end{abstract}


The so-called "new Argentine cinema" is a trend that took place in the mid-1990s, within the framework of a country with economic and social problems, configured in close relation to that context. This is reflected in films that expressed evils that affect Argentine society in the expression of a community devastated by the political-institutional crisis, unemployment and the prevailing discrimination.

Palabras Claves: Nuevo cine argentino, Película Bolivia, Israel Adrián Caetano, Retórica. Keywords: New Argentine Cinema, Movie Bolivia, Israel Adrián Caetano, Rhetoric.

Sumario 1.Introducción 2. Bolivia 3. "Otro" diferente: sujeto de desorden y discriminación 4. Bibliografía

Summary 1.Introduction 2. Bolivia 3. Different "other": subject of disorder and discrimination 4. Bibliography

\section{Introducción}

En el marco de un proyecto mayor sobre los textos de la cultura en clave retórica, nos interesa analizar el lenguaje del llamado "nuevo cine argentino" y, dentro de este movimiento, en esta ponencia, la película "Bolivia" de Israel Adrián Caetano (2001).

A través del film veremos la posibilidad figurativa de su discurso en cuanto a la conformación "orden" y "desorden" en los tejidos de las relaciones sociales, las retóricas de discriminación con sus lógicas de equivalencia y diferencia, construcción y deconstrucción de identidades, formas de consideración de la "otredad" según parámetros que responden a concepciones de raza y/o clase-

Las migraciones de personas en búsqueda de nuevas oportunidades (de países más pobres o en crisis a lugares con mayores oportunidades laborales) producen desacomodamientos, incluso, rupturas en el tejido social ("desorden"), se asientan como minoría en alguna forma de construcción de alteridad, propia de la sociedad que les "da lugar" (con las ambivalencias propias de la hospitalidad) y se generan expresiones de rechazo, cuyas figuras recurrentes son el prejuicio, la discriminación, la exclusión, la xenofobia. Esto se pone de manifiesto en las retóricas acerca del "otro" (inmigrante), que podemos relevar en la sociedad receptora de extranjeros y en sus prácticas sociales.

\section{2. "Nuevo cine argentino": El difuso límite entre ficción y realidad}

El llamado "nuevo cine argentino" es una corriente que se produjo a mediados de la década de los 90 , en el marco de un país con problemas económicos y sociales, configurada en 
estrecha relación con ese contexto. Esto se plasma en filmes que expresan los males que afectan a la sociedad argentina en la expresión de una colectividad devastada por la crisis político-institucional, el desempleo y la discriminación reinante.

La corriente de la filmografía del nuevo cine argentino está conformada por películas con diferentes estilos, pero con una notable índole realista y como dice Luis Barreras con "un lenguaje fílmico que relata la ciudad, la periferia y la nostalgia de una Argentina que no fue" (2002 :3). Está marcado por el carácter independiente de las realizaciones y un cambio en la mirada de mundo. En general, la filmografía de este movimiento construye una contemplación naturalista del mundo, una realidad estética en donde la verosimilitud se refleja en los imaginarios sociales. Sus películas son tónicas, con personajes realistas, bajo presupuesto y en general actores no conocidos. Comenzaron a tener aceptación en el público argentino culto, cosecharon premios internacionales y en general el beneplácito de la crítica especializada. Los principales exponentes en esta filmografía son: Martín Rejtman, pionero con su opera prima "rapado" (1991), Israel Adrián Caetano, Bruno Stagnaro, Pablo Trapero entre otros.

En este cine, por lo general encontramos a sujetos sin esperanzas, sin retorno, lo que responde a la corriente del realismo social. No hay un sentido épico político, como lo que pudimos ver en algunas películas post dictadura como por ejemplo: "La historia oficial" (Luis Puenzo-1986) "La noche de los lápices" (Héctor Olivera 1986), "La amiga" (Jeanine Meerapfel, 1989), solo por nombrar algunas; sino inmersos en un escenario donde prevalece el desempleo, la apatía, la marginalidad. Esto pone de manifiesto ciertos regímenes de visibilidad y marcos sociales de representación y percepción.

El mundo del trabajo, del desempleo y las zonas que el poder hegemónico silencia o sólo emergen como focos de conflictividad criminal son los principales temas que tratan un grupo de películas, sobre todo de Caetano y de Trapero, que pueden caracterizarse como de un "realismo sucio". La calle, la cárcel, la comisaría o la villa miseria como escenarios que funcionan ya no como un soporte pasivo e indiferente, sino como actores determinantes de la suerte de sus protagonistas y de sus vidas. Trapero repite alguna de estas características en sus producciones actuales como Leonera (2008) y Carancho (2010) siendo el sello la corrupción, la marginalidad, la exclusión; lo que los convierte en filmes oscuros y con poca esperanza. 


\section{Bolivia}

"Bolivia" es la primera película de Israel Adrián Caetano solo, la anterior "Pizza, birra y faso" (1997) la había escrito y dirigido con Bruno Stagnaro.

"Bolivia" es una película pequeña, en blanco y negro, filmada en $16 \mathrm{~mm}$. con una duración de 75 minutos. Se desarrolla casi únicamente en un bar, en un tugurio cualquiera de la ciudad de Buenos Aires. Un establecimiento donde se ven siempre las mismas caras: taxistas y desocupados, habitúes que se conocen entre sí y que mantienen una relación de clientesamigos-deudores con el dueño Enrique (Enrique Liporace), ahogan sus penas en un vaso de cerveza mientras sueñan con lograr grandezas en el fútbol o en algún programa de moda en televisión para salir de las deudas y de la marginalidad

Freddy (Freddy Flores) es un boliviano que llega a Buenos Aires con la esperanza de encontrar una vida más digna para él y su familia, pero se encuentra con una ciudad que no es tan amigable como él cree, donde no hay lugar para los sueños. Consigue en el bar de Enrique un trabajo de parrillero, por 15 pesos por día (se gasta 10 para hablar con su familia en Bolivia, en un locutorio "trucho" en el que le cobran según su cara), en ese bar también trabaja Rosa (Rosa Sánchez ) una paraguaya que sueña con volver a su patria.

Los otros personajes, los clientes permanentes son: el Oso (Oscar "oso" Bertea) y su amigo Marcelo (Marcelo Videla), Alberto (Alberto Mercado) los tres taxistas, Héctor, el cordobés, (Héctor Anglade) vendedor ambulante.

Los personajes tienen los mismos nombres de los actores que los representan, jugando con un realismo que opera en la búsqueda de efectos de verosimilitud y autenticidad recurrentes en esta corriente cinematográfica: son los Freddys, las Rosas, los Enriques, los "osos" que representan los sujetos de un destino sin retorno.

En este bar el ambiente casi siempre está cargado. La ilegalidad está presente, primerísimos planos de rostros desencajados, pases de sugestivos "paquetitos" de un bolsillo al del compañero. Freddy y Rosa, en su carácter de extranjeros e indocumentados, Enrique con un pasado (que no se explicita) pero que más de una vez le recuerda el Oso: -"cuando yo te tuve que sacar del pozo".

Todo está listo para explotar: hay silencios, hay miradas que matan, hay cuerpos que chocan y se murmuran cosas sin que nadie lo note.

La presencia de Freddy desencadena las broncas contenidas. Se lo ve como un individuo que viene de afuera - ni siquiera reconocen su nacionalidad sino que lo generalizan por los rasgos físicos y la tonada, le dicen peruano, "andá allá donde se juntan los negros latinoamericanos..." - que le quita el trabajo a los de "aca". Rosa, en cambio, es objeto de 
deseo de todos. Se crea una fraternidad entre Rosa y Freddy, quienes terminan acostándose juntos cuando van a bailar a un boliche de la comunidad boliviana; la noche que Freddy duerme con ella es la única en la que no lo hace sobre una mesa de bar después de pedir un café.

El film está cargado de muestras explícitas de discriminación, Freddy es parado por la policía a la salida del trabajo "por aportación de cara", lo requisan, le preguntan de dónde viene vine a ver un familiar, - sabés que no podés trabajar. - Qué mierda tiene, - boludeses. - Si te vuelvo a ver por acá te llevo preso. Los clientes del bar no sólo lo miran con desprecio sino que van insultándolo en forma creciente hasta llegar al día de la tragedia; ese día el Oso rebasa el límite de sus problemas económicos y familiares, se emborracha, Enrique quiere sacarlo del bar - Vos te creés que yo soy ese bolita que está traspirando ahí, a mí me tenés que respetar, Marcelo lo quiere sacar, se trenzan en una pelea, Freddy intenta separarlos "Quien me va a sacar un paraguayo de mierda, un boliviano de mierda..." "Los bolivianos son todos unos putos y le pega.... Te venís a sacar el hambre y dejas sin laburo a los pibes de aca-. El boliviano lo golpea, él no tiene derecho. El Oso lo mata.

Freddy era un indocumentado.... Todo queda como si nada hubiera pasado, al final de la película un primer plano de Rosa comiendo sola y de Enrique, que vuelve a colocar el cartel "Se necesita barrillero".

La sensación de realismo y cotidianeidad que transmite este relato nos permite conocer a sus personajes y saber por qué actúan como lo hacen. Así, el retrato de la xenofobia que dibuja Caetano no es un ángulo recto, el racismo no se presenta per se, sino como la manera de expiar las propias frustraciones. El inmigrante es una presa fácil, un objeto en el que descargar los problemas diarios. De esta manera, las dificultades económicas de los taxistas que frecuentan el bar es motivo suficiente para agredir a Freddy.

\section{4. “Otro" diferente: sujeto de desorden y discriminación}

En una entrevista realizada por Lorena García en La Nación espectáculos el 10 de abril de 2002, Caetano recuerda que "un grupo de hinchas argentinos mató a golpes a un brasileño porque gritó un gol que Nigeria le hizo a la Argentina. Creo que ese racismo fue alimentado hace muchísimo tiempo, desde Roca. Pero creo que la gente no es xenófoba. Creo que ha habido un discurso muy perverso desde los gobiernos que todo el tiempo han tratado de delegar culpas y confundir a la gente para que no se fijen en qué es lo que realmente pasa." (... ) "Tal vez la película "Bolivia" podría haberse llamado "Perú" o "Paraguay" y hasta "Jujuy". Desde sus diálogos juega con esa concepción generalizada -sobre todo entre los 
porteños- de que el interior es como un agujero negro, y el resto de los países sudamericanos conforma un bloque homogéneo al que la Argentina no pertenece, y en donde es lo mismo un peruano que un boliviano, y hasta un jujeño podría también confundirse."

En la construcción de las diferencias aparecen formas de discriminación basada en retóricas de la "otredad" compartidas por un imaginario colectivo local (lo dice Caetano, pueden ser bolivianos, peruanos, jujeños; tiene rasgos físicos y costumbres que se les atribuye a un "otro" que rechazamos). Los sujetos inmigrantes -y esto pasa en todos los lugares del mundo y con cualquier tipo de personas, aunque se agudiza con pobres y mestizados-, se inscriben en un orden social basado en la diferencia o en el "desorden".

Argentina ha marcado un notorio ascenso de migraciones limítrofes en las últimas décadas del Siglo XX, el censo de 1991 ha marcado más del 50\% de presencia de limítrofes en el conjunto de los extranjeros principalmente de Bolivia, Paraguay, Uruguay, Perú y Chile que se han asentado en centros urbanos. La base de subempleo es alta en estos inmigrantes como es alto el grado de precariedad del empleo en general, mayormente contratados "en negro" por la irregularidad en la documentación y en condiciones de explotación, sumado a la imposibilidad de acceder al sistema de previsión social y cobertura de salud.

Decíamos con María Inés Loyola en Fronteras culturales... (2010): las situaciones de rechazo, de prejuicio, o al menos de diferenciación hacia extranjeros que hoy existen en las grandes ciudades que han sido objeto de inmigraciones de países limítrofes, no son las únicas o sólo configuran un aspecto de la consideración del "otro". Si toda cultura supone un "nosotros" que comparten códigos y formas simbólicas, además de una historia y una lengua, el "otro" opera por diferenciación y en la comparación con el "nosotros" se torna evidente y encuentra obstáculos en la comunicación. Pero la "otredad" es casi una condición normal de la vida cotidiana y de la convivencia social. De lo que aquí se trata es de las características de esa "otredad" que incluye a los extranjeros (sobre todo de países latinoamericanos) y también a los pobres y marginados, aunque nativos. Se trata entonces de cómo nos relacionamos con ese "otro" extraño y el grado de distancia que nos separa, así como la carga valorativa que tenemos hacia él.

"Bolivia" muestra una pequeñísima parte de esta problemática, el relato llega al extremo del asesinato del "boliviano" como expiación a la desesperanza. En este cuento donde el enfrentamiento es "entre pobres y desclasados", los otros personajes del film también son "extranjeros" en su propio país, como plantea García Canclini (2004), no siempre las extranjerías se producen por la inmigración a otros países sino también "por desacomodar las clasificaciones convencionales de unos y otros grupos, aun en la misma sociedad" (:5). 
Todos de alguna manera pertenecen a esa categoría de "extranjeros" o marginados que no disfrutan los derechos de un ciudadano y actúan como extranjeros respecto del orden legal y oficial: transgresiones individuales o redes colectivas de trabajadores indocumentados, comerciantes ilegales o desocupados.

En lo visto hasta aquí, el "otro", en este caso el inmigrante boliviano, origina el "conflicto", el desorden". La construcción de la diferencia se advierte en lo dicho y también en lo no dicho lo que el lenguaje visual del cine permite paneos por rostros y situaciones cargadas de tensión. Las opiniones acerca de ese otro siempre están cargadas de una consideración negativa, descalificante (nego..., latinoamericano...bolita...). Las personas (o la sociedad) con prejuicios parece haber decidido negativamente antes de toda prueba. Esta noción de prejuicio, en el empleo que se hace desde la psicosociología, no se refiere tanto al prejuicio contra individuos sino a los prejuicios hacia grupos enteros.

También es común advertir las contradicciones en las políticas oficiales relacionadas con la inmigración. Por un lado, los gobiernos crean instituciones destinadas a ocuparse del bienestar de los inmigrantes y a favorecer las relaciones armoniosas entre los grupos, pero, asimismo "consienten" la discriminación por parte de las mismas reparticiones oficiales. Tampoco se observa el papel del estado en relación a la discriminación económica que sufren las minorías inmigrantes o el hostigamiento por parte de la policía que sólo está motivado por lo que se denomina habitualmente "portación de cara" (la escena de la requisa a Freddy en "Bolivia" lo muestra claramente). Estas ambiguas prácticas permiten suponer que las actitudes discriminatorias y prejuiciosas se perpetúan gracias a mecanismos culturales que tienen su base en las representaciones sociales acerca del "otro". También resulta interesante aquí la explicación acerca del chivo expiatorio en tanto medio para descargar los prejuicios.

Dice Stella Martíni: "En la naturalización de los discursos hegemónicos (...) se produce la representación de los que son colocados en el campo de la ilegalidad, los 'otros', delincuentes, marginales, 'los sospechosos de siempre' (pobres, jóvenes, villeros), y en un proceso metonímico resultan también excluidas las geografías y la cultura de la pobreza (barrios y villas precarias, zonas marginales de las ciudades, viviendas precarias, lugares de esparcimiento, realidad del tiempo libre por efectos del desempleo)" (2002: 88). Variables que aborda esta corriente llamada "nuevo cine argentino" y que abre a futuras indagaciones al respecto. 


\section{Bibliografía}

Cagginano, Sergio (2005): Lo que no entra en el crisol. Inmigración boliviana, comunicación intercultural y procesos identitarios. Prometeo Libros. Buenos Aires.

Campero, Agustín: (2008) Nuevo Cine Argentino. De Rapado a Historias extraordinarias. Universidad Nacional de General Sarmiento.

García Canclini, Néstor: (2004) Diferentes, desiguales y desconectados. Mapas de la interculturalidad. Gedisa. Barcelona.

Loyola María I, Villa María J: (2010) Fronteras culturales en Actas del Congreso Internacional de Lengua y Literatura en el año del Bicentenario. ESBN: 978-950-33-0790-8.

Margulis, Mario: (2003): Globalización e Identidad Cultural. Ed. Ciccus. Buenos Aires

Martini, Stella: (2002) "Agendas Policiales de los medios en la Argentina: La exclusión como un hecho natural", En Gayol, S. Y Kessler, G: Violencia, delitos y justicias en la Argentina. Manantial. Universidad Nacional de General Sarmiento.

\section{Forma de citar este artículo en bibliografías}

VILLA, M.J. (2011): "Extranjero/extraño: sujetos de desorden y discriminación. El caso de Bolivia, de Israel Adrián Caetano", en Revista PANGEA, 2, páginas 171 a 178. Red Académica Iberoamericana de Comunicación. Recuperado el _ de __ de 2 de: www.revistapangea.org 